\title{
PAULO FREIRE E ANTONIO GRAMSCI: A FILOSOFIA DA PRÁXIS NA AÇÃO PEDAGÓGICA E NA EDUCAÇÃO DE EDUCADORES
}

\author{
Peri Mesquida \\ Pontifícia Universidade Católica do Paraná- PUCPR
}

\section{RESUMO}

Durante sua permanência no Chile (1964 - 1969), Paulo Freire reencontrou-se com o materialismo dialético e histórico e aprofundou as leituras das obras de Karl Marx e Friederich Engels. No entanto, entre os autores marxistas com os quais entrou em contato quem mais o impressionou foi Antonio Gramsci (1893 - 1937). Iremos, pois, neste artigo, aproximar conceitos de Gramsci com outros de Paulo Freire (1921 - 1997), à luz, no caso de Freire, em especial, da obra intitulada Pedagogia do Oprimido e, no que diz respeito a Gramsci, usaremos, em particular, os Quaderni del carcere, edição de 1975. Procuramos, também, verificar o que pensam Freire e Gramsci sobre a educação do educador. Freire começou a refletir sobre a educação e a colocar em prática suas ideias pedagógicas a partir, em especial, da metade da década de 1950, enquanto Gramsci, italiano, desenvolveu sua obra política, sociológica e filosófica, em particular, de 1916 a 1937. Freire centrou sua atenção sobre aqueles que ele chamava de "oprimidos" do capitalismo periférico, isto é, sobre aqueles a quem a "palavra havia sido negada"; Gramsci centrou sua reflexão e sua ação, particularmente, sobre os operários italianos e sobre os que sofriam a opressão fascista na Itália. Tanto em um caso quanto no outro, tratava-se do Estado utilizando continuamente a força (coerção) e às vezes a persuasão (formação da mentalidade) para exercitar o poder de maneira a não ter qualquer tipo de oposição; Freire buscou em autores, sobretudo europeus, mas também norte-americanos (Horace Mann, C. Rogers, J. Dewey), as idéias que poderiam lhe oferecer elementos teóricos sólidos para construir um "edifício' epistemológico capaz de dar sustentação a uma teoria da educação que tivesse condições de nutrir uma prática pedagógica libertadora; Gramsci buscou as categorias filosóficas e sociológicas que serviram de base para sua reflexão e sua ação, particularmente em Karl Marx, F. Engels, e Lênin.

Palavras-chave: educação, filosofia da práxis, pedagogia, libertação.

\section{PAULO FREIRE AND ANTONIO GRAMSCI: A PHILOSOPHY OF PRAXIS IN PEDAGOGICAL ACTION AND IN THE EDUCATION FOR EDUCATORS}

\begin{abstract}
During his stay in Chile (1964 - 1969), Paulo Freire reunited with dialectical materialism and historical readings and deepened the works of Karl Marx and Friedrich Engels. However, among the marxist authors with whom he interacted who most impressed him was Antonio Gramsci (1893 - 1937). We will therefore in this article, Gramsci's approach with other concepts of Paulo Freire (1921 - 1997), the light in the case of Freire in particular the work entitled Pedagogy of the Oppressed, and with regard to Gramsci, we will use, in particular, Quaderni del prison, the 1975 edition. We try to also check what they think Freire and Gramsci on the education of the educator. Freire began to reflect on education and to implement his ideas from teaching, in particular, half of the 1950s, while Gramsci, Italian, developed his political, sociological and philosophical, in particular, from 1916 to 1937. Freire focused its attention on those he called "the oppressed" of peripheral capitalism, that is, on those whom "the word had been denied" Gramsci focused their
\end{abstract}


reflection and action, particularly on the Italian workers and those on oppression suffered in Fascist Italy. Both in one case as in others, it was the state continuously using the force (coercion) and sometimes persuasion (forming minds) to exercise the power so as not to have any kind of opposition, Freire sought in authors, especially Europeans but also Americans (Horace Mann, C. Rogers, J. Dewey), ideas that could offer elements to build a solid theoretical 'building' epistemological able to support a theory of education that have been able to nurture a liberating educational practice; Gramsci sought the philosophical and sociological categories that formed the basis for your reflection and action, particularly in Karl Marx, F. Engels, and Lenin.

Keywords: education, philosophy of praxis, pedagogy, liberation.

\section{Introdução}

Neste artigo procuraremos aproximar o pensamento-ação desses dois autores (teóricopráticos, como diria Gramsci), Antonio Gramsci e Paulo Freire tanto no que diz respeito aos principais conceitos trabalhados por Freire quanto no que tange à educação dos educadores, ou formação de professores.

Para começar, mostraremos que há um nexo que os une e aproxima a sua teoria e a sua prática: o amor comum pelos oprimidos e a confiança nas possibilidades da educação enquanto fator de transformação social: os oprimidos brasileiros, mas também os do resto do mundo, em Paulo Freire; os oprimidos italianos, mas os do resto do mundo, em Gramsci. Freire queria que os "condenados da terra" construíssem a consciência crítica e política, utilizando para tanto a educação; Gramsci queria mudar a situação de opressão vivida pelos operários italianos por meio da ação política sob a forma de uma "guerra de posição".

Freire e Gramsci acreditavam que a tomada de consciência era o primeiro passo que os oprimidos deveriam dar na direção da libertação. São, portanto, autores sensíveis à problematização das possibilidades da educação.

Refletiremos, pois, sobre a influência de Gramsci sobre o pensamento de Paulo Freire e, portanto, sobre a proximidade das suas idéias e de sua prática e também sobre a visão de ambos sobre a formação e o papel do educador/intelectual orgânico das classes subalternas.

\section{Gramsci e Freire: confluências e influências}

1.1 O meio: Nos Quaderni, Gramsci observa que o meio é educador e como tal deve também ser educado (GRAMSCI, 1975). Gramsci, nesta caso, segue Karl Marx na sua terceira tese sobre Feuerbach, na qual Marx afirma que o educador dever ser educado: "a doutrina materialista sobre a mudança das contingências e da educação esquece de que tais contingências são mudadas pelos homens e que o próprio educador deve ser educado. Deve por isso separar a sociedade em duas partes uma das quais é colocada acima da outra. A coincidência da alteração das contingências com a atividade humana e a mudança de si próprio só pode ser captada e entendida racionalmente como práxis revolucionária"(MARX, 1977). Para Gramsci, as relações sociais das quais os educandos participam, a família, os vizinhos, a comunidade devem também ser objeto da ação educativa. Assim, o educador precisa levar em conta o contexto social e cultural dos educandos. É necessário, pois, que o educador entenda o contexto, matas também é importante que o meio possa escutar o educador. Isso leva o educador a valorizar o saber 
popular, pois o educador, como intelectual, "compreende, sabe e sente", enquanto o homem "simples" das massas segue o caminho inverso: "sente, compreende e sabe". Isso quer dizer que o educador sabe, mas nem sempre compreende e muito menos sente, na medida em que o homem simples sente, mas nem sempre compreende e sabe (GRAMSCI, 1989, p. 138-9).

Paulo Freire sempre disse e escreveu que o processo de ação pedagógica começa pelo meio que envolve o educando: "antes de aprender a dizer a palavra é fundamental que o oprimido saiba ler o mundo" (FREIRE, 2002, p. 24). O meio oferece ao educador os elementos sócio-antropológicos em forma bruta que o educador devolve ao meio, pela ação pedagógica, carregados de densidade epistemológica. São as "palavras geradoras", originadas do meio onde vivem os educandos. Isso significa que é necessário suscitar em cada indivíduo e no grupo de educandos, a capacidade de formar-se a si mesmo de maneira a dominar o contexto, tornando-se mestre do seu próprio destino (FURTER, 1983).

1.2 Escola e vida: Para GRAMSCI (1975), há um nexo entre a escola e a vida e uma união entre a palavra e a vida. O educador deve conceituar os vocábulos e dotá-los de vida por meio da densidade histórica e política que eles podem ter: "A identificação das palavras e sua conceituação devem ser efetuadas levando em conta o contexto cultural e histórico" (GRAMSCI, 1975, p. 1545). Assim, Gramsci crê que a escola (em especial, os círculos de cultura - circole di cultura - nos Conselhos de Fábrica), a vida do educador e a do educando são inseparáveis. Na medida em que a prática pedagógica é uma ação baseada fundamentalmente na palavra, a escola e a vida não podem estar separadas. Freire acreditava que ao aprender as palavras com seu peso cultural e histórico, o educando construiria uma consciência política capaz de ajudá-lo a se livrar da opressão. Para Paulo Freire, a conquista da história por aqueles e aquelas a quem foi negado o direito de se fazerem atores de sua história, passa pela conquista da palavra: "é necessário dar a palavra aos miseráveis para que eles possam 'pronunciar' o mundo" (FREIRE, 1979, p. 62), no sentido não somente de dizer as coisas com convicção e de ser capaz de anunciar o que pensam enquanto uma boa nova (anunciar vem de nuntius =menssageiro), mas também "pronunciar o mundo" no sentido de "transformá-lo e transformando-o, torná-lo humano para a humanização de todos" (FREIRE, 1979, p. 62). Trata-se, portanto, não somente de uma palavra anunciadora da boa nova, mais também transformadora. A consciência de si e da realidade dá ao oprimido a coragem da qual ele necessita para se mostra ao mundo.

1.3. A educação para a liberdade: Gramsci pensava que era preciso formar o homem para que ele fosse "capaz de pensar, de governar e de controlar aqueles que governam". Assim, a escola poderia não somente "formar o cidadão, no sentido do Iluminismo, mas também o cidadão com condições políticas de governar” (GRAMSCI, 1975, p. 487).

Para Paulo Freire, a consciência do oprimido foi moldada pela concepção de mundo do opressor. Dessa maneira, o oprimido adere aos valores, às ideologias, no sentido de falsa consciência, como as entende K. Marx na Ideologia alemãa, aos interesses do opressor, fato que não lhe permite ser livre. Para Marx, até agora, "os homens formaram sempre idéias falsas de si mesmos, sobre aquilo que são ou deveriam ser. Organizaram as suas relações mútuas em função das representações" (MARX, 1974). Por isso, Paulo Freire, seguindo o pensamento de Albert Memmi (2004), afirma que a consciência do oprimido abriga a consciência do opressor. A educação pode ser a força libertadora do oprimido - dos oprimidos - pois "o homem na se liberta sozinho" (FREIRE, 1977, p. 85), e a educação é, 
por natureza, comunitária. A libertação é também comunitária: os homens se libertam na medida em que se unem uns com os outros (nos círculos de cultura, por exemplo). Mas, a educação que pode promover a libertação não é qualquer educação. Como já vimos, Paulo Freire chama de "bancária" a educação na qual o educador "deposita" o saber na cabeça do educando (como alguém que deposita dinheiro no banco). Este deve escutar, obedecer e mostrar ao "mestre" que compreendeu os conteúdos ensinados, sendo o exame a retomada do "dinheiro" depositado no banco. A relação professor/aluno é vertical. Para superar a educação bancária, Paulo Freire propõe o diálogo como método e prática educativa. Com o diálogo, a relação não é mais entre um "mestre" que tudo sabe e um "aluno" que nada sabe, mas entre duas pessoas que aprendem juntas, justamente porque o educando não é uma "tabola rasa" sobre a qual o "mestre" imprime o saber. O educando tem toda uma história de vida, de experiência de prática que é necessário levar em consideração durante o processo de aprendizagem. Abre-se, assim, o caminho para a colaboração e para a "síntese cultural". Abre-se o caminho para a libertação. De sujeito (pessoa submissa), o educando torna-se cidadão apto a governar, a marcar a direção, a indicar o caminho a seguir.

1.4. Os círculos de cultura: Gramsci propõe os "circole di cultura" (GRAMSCI, 1975, p. 484) como espaços onde se produz uma nova cultura a partir da união entre a concepção de mundo dos dominados (senso comum) e a visão de mundo dos intelectuais revolucionários (filosofia da práxis). Os círculos de cultura poderiam substituir a escola capitalista dominada pelo Estado e pela Igreja. Seriam "locae" onde se construiria uma nova cultura e onde teria inicio uma "reforma intelectual e moral", pela educação. Os professores, nos "circole di cultura", não seriam "instrutores", mas "animadores culturais", chamados por Antonio Gramsci de "conselheiros", "guias que ajudam os educandos utilizando como método a maiêutica" - o método de Sócrates, ou a arte de fazer com que o saber venha à luz (GRAMSCI, 1975, p. 484). Os círculos de cultura se localizariam no interior dos Conselhos de fábrica, uma organização autônoma com relação aos modelos "escolares" burgueses. Assim, os Conselhos de fábrica seriam a "escola do futuro", sem vínculo com a escola burguesa onde são mantidas as divisões do trabalho e as divisões sociais, consistindo em instituições fragmentárias e sócio-fragmentadoras. Portanto, os Conselhos de fábrica, com seus círculos de cultura, seriam um meio para a construção da revolução proletária e a construção de um novo homem e de uma reforma intelectual e moral (GRAMSCI, 1970, p. 520).

Para Paulo Freire, os "círculos de cultura" seriam espaços onde os educandos se reuniriam para construir uma nova concepção de mundo apta a ajudá-los a conquistar a liberdade. Os círculos de cultura, como em Gramsci, não teriam professores, mas "animadores culturais" a conduzir o processo de aprendizagem e de construção de um novo saber tendo em vista uma nova sociedade. Seu método: o diálogo - a maiêutica. Assim, o círculo de cultura é uma "escola" diferente na qual os problemas comuns dos educandos e dos educadores são discutidos visando uma reforma intelectual e política: humana. Nos círculos de cultura não haveria lugar para a educação "bancária" e para as "lições" tradicionais que exercitam somente a memória dos educandos, que não constroem um saber novo, somente reproduzem o conhecimento acumulado (GADOTTI, 1996). Isso significa que os círculos de cultura tomariam o lugar da "escola" tal como ela se apresenta com sua divisão do trabalho e suas divisões de classe, transformando-a em espaços de problematização do saber acumulado e da forma como a vida é produzida, a partir do conhecimento existente na comunidade, um saber que tem sua origem nas "palavras geradoras" e nos "temas geradores". 
1.5. Hegemonia e a formação de uma consciência crítica: Gramsci tomou o conceito de hegemonia do pensamento de Lenin e Bukharin. Trata-se de uma palavra de origem grega que significa "direção", ou o exercício do poder por um general do exército (guia supremo - comandante), aquele que exerce o poder lançando mão da persuasão e, também, se necessário, da coerção.

Gramsci, seguindo a tradição política marxista, emprega a palavra hegemonia em sentido duplo: direção política e ação cultural de um grupo sobre outro grupo social. Dessa maneira, para Gramsci, é fundamental induzir as massas populares a superar seu "espontaneísmo" destituído de crítica (mistura de uma cultura "folclórica" com a religião e a cultura das classes superiores). As "massas" precisam atingir o nível da crítica "com um espírito criador - pela construção de uma concepção de mundo nova, revolucionária, transformadora. Ao escrever que "toda relação de hegemonia é necessariamente uma relação pedagógica" (GRAMSCI, 1975, p. 1331), Gramsci queria fundar uma "pedagogia social" das massas populares (pedagogia dos oprimidos?) por meio da educação e pela atividade política militante (para Paulo Freire, a educação é sobretudo uma atividade política). Gramsci fala constantemente de uma consciência histórica autônoma, de uma representação do mundo nova e libertadora. Ele evoca igualmente a formação de uma consciência coletiva, a construção de uma consciência crítica, formulas que nós encontramos seguidamente na obra de Paulo Freire.

Os círculos de cultura tanto quanto os conselhos de fábrica seriam lugares onde se praticaria uma pedagogia política ou uma política pedagógica (os círculos de cultura são organizações pedagógico-políticas; os conselhos de fábrica, organizações políticopedagógicas). Os dois organismos constituiriam lugares da formação da consciência (onde seria construída uma "nova mentalidade") e de preparação das massas oprimidas (ou operários/camponeses) para o exercício da hegemonia cultural e política.

O conceito de "conscientização", encontrado na obra de Álvaro Vieira Pinto, enquanto ação dos dominantes sobre os dominados, torna-se em Paulo Freire um conceito chave, mas como a interiorização, a introjeção de uma visão de mundo libertadora capaz de ajudar os oprimidos a sair da sua condição de opressão e de levá-los na direção da liberdade pela educação - uma educação libertadora (realiza a práxis - une reflexão e ação) porque faz a crítica da realidade tal como ela se apresenta indo á raiz da opressão. Daí, então, o oprimido pode tomar o futuro nas próprias mãos e começar a lutar para mudar a realidade, para mudar o mundo que o oprime: trata-se, portanto, de uma ação transformadora. Dessa maneira, ele passa a ser uma pessoa que não se "con-forma", isto é, alguém que não assume mais a forma da sociedade tal qual ela é, mas quer construir um mundo novo e melhor que o conduz da consciência "mágica", "ingênua", à consciência crítica e libertadora (FREIRE, 1974a).

1.6. Filosofia e filósofos: Gramsci (1975) considera que todos os homens são filósofos e percebe a filosofia como uma reflexão crítica sobre o ser humano - uma reflexão que permite ao homem se descobrir enquanto homem. Seguindo Teillard de Chardin, Paulo Freire (1977) afirma que a humanização não é somente um processo biológico - a humanização é também histórica e libertadora. Platão confiava o poder político aos filósofos a fim de que eles fossem educadores dos cidadãos. Assim, a educação seria realizada graças ao poder político. Contudo, a finalidade autêntica do exercício desse poder pode vir a ser a justiça (LÉVÊQUE ET BEST, 1969; FURTER, 1983). Dessa maneira, o 
filósofo que deseja encarnar sua reflexão em uma ação na sociedade dos homens, aquele que procura promover a liberdade e a universalidade, tem por único meio a educação. Nessa linha de pensamento, Paulo Freire afirma que o homem que faz uma reflexão sobre si mesmo e sobre o mundo tem a possibilidade de tornar-se ator, construtor da sua própria história (FREIRE, 1974b). Refletindo sobre a educação do educador, Gramsci no Ordine Nuovo (1987), defende a idéia de que além de educar-se a si mesmo, o educador deveria, humildemente, ser educado pelo educando. Esta posição é encontrada também em Paulo Freire para quem não existe docência sem discência, isto é, educador e educando educamse no processo de aprendizagem. (FREIRE, 1996)

1.7. Verdade e revolução: Nos Cadernos do Cárcere, GRAMSCI (1975, p. 1434) afirma que a verdade é revolucionária quando ela se faz arma dos oprimidos (operários) contra as mentiras da ideologia dominante que produz uma falsa consciência da realidade. Portanto, Gramsci, seguindo K. MARX (1977, p. 34), acreditava que "as idéias dominantes em uma formação social são sempre as idéias das classes dominantes".

Para Paulo Freire o mundo é produto da ação do homem, do homem emancipado, mestre de suas idéias e portador de idéias que podem contribuir para mudar a direção da história. São as "idéias motoras". Assim, o homem que não pode agir, que se conforma ao "mundo" e à sociedade tal como se apresentam, perde sua humanidade. Dessa maneira, a educação ou ela é libertadora ou ela não é educação, segundo a visão de Paulo Freire e segundo o sentido que ele atribuía à prática pedagógica (FREIRE, 1971).

1.8. Os marginalizados rurais e os marginalizados urbanos: Paulo Freire começou sua obra pedagógica no meio rural, mas não se limitou ao campo, estendo sua ação para o meio urbano. Gramsci centrou sua reflexão sobre a situação dos marginalizados e trabalhadores urbanos.

No meio rural há a tendência dos agentes educativos de propor uma formação essencialmente utilitária e profissionalizante numa perspectiva de modernização (levar a essas populações os avanços da tecnologia para melhorar sua técnica) da vida rural à qual as pessoas desse meio possam se integrar. Para as populações marginalizadas das cidades o que se impõe é, antes de tudo, uma formação política capaz de lhes dar coragem par lutar por melhores condições de vida.

II. Educação de educadores: Karl Marx na terceira Tese sobre Feuerbach afirma que o "educador precisa ser educado" (MARX, 1987, p.12). Nesse sentido, surgem necessariamente algumas perguntas: afinal, quem educa o educador e para qual finalidade? Marx, na mesma Tese, situa a educação do educador no contexto da praxis revolucionária, isso porque ele está pensando no educador engajado no projeto de uma nova sociedade. Sua reflexão e sua ação, dessa maneira, estão intimamente relacionadas com um tipo de educação: a educação como ação transformadora.

Gramsci defende uma educação que forme o homem de modo que ele seja capaz de pensar, de governar e de controlar aqueles que governam e, para isso, ele precisa necessariamente passar de uma visão de mundo fundada no senso comum para uma concepção de mundo filosófica. $\mathrm{O}$ educador do educador, assim, seria formado de maneira a desenvolver sua práxis pedagógica como um "intelectual orgânico" das classes proletárias. O educador, intelectual, não somente elabora a visão de mundo dessas classes como difunde e infunde 
na classe de origem o sentido de uma ação contra-hegemônica. Para Freire, entre outras funções, o educador é educado para fazer com que o educando passe da consciência ingênua para a consciência crítica, isso na medida em que ele decodifica a visão de mundo dominante e codifica a nova visão de mundo do educando (FREIRE, 1980). Isso porque Paulo Freire acredita que a educação, na medida em que alcança a consciência do homem oferecendo-lhe as condições para conhecer o mundo, pelo saber, pode realizar nele uma "metanóia", uma conversão, uma transformação radical. E a metanóia não é somente uma mudança interior, mas uma mudança de concepção de mundo que se exterioriza em forma de uma práxis libertadora. Uma práxis que se concretiza fundada na esperança da conquista de uma vida melhor e mais humana.

Quando pensa na libertação do oprimido, Paulo Freire tem os olhos voltados para o futuro fazendo uma crítica (“denúncia”) radical ao presente. Isso porque, segundo Furter (1974, p. 152), "o princípio da esperança que dá vida à utopia faz da crítica do presente em Paulo Freire, o momento decisivo da construção de uma utopia militante e concreta". Essa maneira de perceber a prática pedagógica de educação de educadores se relaciona diretamente com o conceito grego da "Paideia" que coloca o homem no centro do pensamento educacional. Trata-se do homem livre, dotado da "Aretê" (virtude), e o homem livre (eleuteros) se opõe ao escravo (doulos), oprimido. Portanto, a verdadeira educação tem como objetivo oferecer ao homem as condições para alcançar a finalidade da vida: a humanitas. Assim, a educação do educador centrada na "Paidéia", "vem a ser um poderoso elemento de resistência na luta do homem pela liberdade, na sua humanização" (JAEGER, 1989, p. 395).

A liberdade enquanto utopia é o sonho sonhado que se atualiza pela ação revolucionária da Paidéia metamorfoseada em palavra (logos) anunciadora da libertação. Uma palavra que é também o sinal da liberdade. Por isso ela pode ser chamada de palavra utópica (FREIRE, 1977, 122). Dessa maneira, Paulo Freire pode anunciar a utopia enquanto ação revolucionária na formação do educador: "a utopia é revolucionária porque ela é o anúncio de um mundo que se humaniza" (FREIRE, 1971, p. 43). Se, para Paulo Freire, a utopia é parte integrante da educação do educador, ela não deixa de ser um elemento fundamental para a libertação dos "simples" construindo uma "vontade coletiva" ou um verdadeiro "otimismo da vontade", para Antonio Gramsci (GRAMSCI, 1975, p. 1058). Para ele, a utopia estabelece um nexo fundamental entre os educadores como "intelectuais e o povo", propiciando aqueles a difusão do "humanismo" e procurando "resolver uma série de problemas vitais dos humildes" (GRAMSCI, 1975, p. 2292). Portanto, se Gramsci continuasse sua reflexão nos Quaderni e a estendesse na direção da educação dos educadores, como o fez ao escrever sobre os intelectuais, ele colocaria a utopia como uma categoria teórico/prática indispensável à sua formação.

Na obra Pedagogia da autonomia (1997), Paulo Freire indica determinados "saberes necessarios" à educação do educador. Entre eles destaca a "rigorosidade metódica. Tratase de um saber que reforça a capacidade crítica do educador e do educando, "sua curiosidade, sua insubmissão" à educação bancária que transforma o educando em recipiente de um saber de cuja produção não participou criticamente. Por isso, Freire observa que “o ensinar não se esgota no 'tratamento' do objeto, superficialmente feito, mas se alonga à produção das condições em que aprender criticamente é possível. Condições que implicam a presença de educadores rigorosamente curiosos, persistentes" (FREIRE, 1997, p. 29). Assim, se a modernidade nos influenciou metodologicamente, principalmente 
com Descartes, na medida em que buscou um método seguro na obtenção do conhecimento, pois se considerou que somente o pensamento (cogito) poderia nos conduzir à verdade e que os conhecimentos decorrentes das percepções sensoriais não seriam confiáveis ao universo do conhecimento, Freire considera fundamental para uma educação voltada para a autonomia, libertar-se dessa concepção, pois o compromisso do educador "não é com uma determinada teoria a ser 'comprovada', mas com o desvelamento da realidade que, por mais competente que seja o exercício, será sempre maior que a capacidade de apreendê-la" (FREIRE, 2008, p. 371). O rigor metodológico, para Freire, representa o elemento primeiro e fundamental para uma prática educativa autônoma. Essa preferência se dá, para ele, porque a prática dos educadores está investida de um compromisso ético-político que não pode ser dissociado do testemunho de vida e do que ele chama de "competência profissional". Portanto, aprender a "pensar certo", isto é, com rigor metodológico, é fundamental na educação do educador, pois "quem pensa certo, mesmo que, às vezes, pense errado, é quem pode ensinar a pensar certo" (FREIRE, 1996, p. 30). Da mesma forma, Gramsci nos Quaderni (1975), realça a importância do rigor metodológico, do pensar certo na ação do intelectual (educador, diríamos), quando discute a respeito dos "princípios do método" de que precisa estar imbuído o intelectual engajado na ação junto aos "homens simples". Diz ele que o primeiro princípio é a capacidade de "julgar", pois o juízo é ação e ação consciente, crítica (juízo=crisis). Mas, para julgar "certo" é fundamental "conhecer" (segundo princípio), e para conhecer "é preciso saber tudo o que é possível saber"(terceiro princípio). E, conhecer é ter "contato com a realidade viva e em movimento", dos humildes. Daí, a importância de um conhecimento, de um saber e de um juízo "críticos", rigorosos, metódicos (GRAMSCI, 1975, p. 1946) como elementos imprescindíveis à educação do educador.

Paulo Freire destaca ainda: a) a pesquisa; $b$ ) a reflexão sobre a prática e c) aprender que ensinar não é transferir conhecimento, como saberes necessários à educação do educador (FREIRE, 1997). Neste sentido, Gramsci também acentua a importância da "unidade de teoria e prática", como filosofia da práxis, na ação engajada dos intelectuais (GRAMSCI, 1975, p. 473-474); faz, ainda, uma dura crítica á escola "tradicional" que não desenvolve a produção do conhecimento novo, pois a "ciência é uma categoria histórica e não atrelada a uma verdade científica definitiva", (GRAMSCI, 1975, p. 1456) e está a cada momento exigindo novos conceitos, mas (a escola) atua para a manutenção do status quo, reproduzindo o conhecimento acumulado de forma acrítica $(1975$, p. 2047). Neste sentido, Gramsci dá ênfase à criação da cultura, em particular de uma nova cultura que leve em consideração as massas populares. Para ele, "criar uma nova cultura não significa individualmente fazer descobertas 'originais', significa também e especialmente difundir criticamente verdades já descobertas, 'socializá-las', por assim dizer e fazer delas a base da ação vital, um elemento de coordenação e de ordem moral e intelectual" (GRAMSCI, 1975, p. 1377-1378). E conclui, referindo-se aos intelectuais (educadores freireanos): "Que uma massa de homens seja conduzida a pensar coerentemente e de modo unitário a realidade presente é fato 'filosófico' mais importante e 'original' que a descoberta por um 'gênio' filosófico de uma nova verdade que permanece patrimônio de um pequeno número de intelectuais" (GRAMSCI, 1975, p. 1378). 


\section{Considerações finais}

Essa análise interpretativa e comparativa da forma de pensar desses dois autores mostra com clareza não somente a proximidade do seu pensamento, mas, em particular, a influência exercida pelas idéias de Antonio Gramsci sobre a construção da teoria da educação ou da teoria pedagógica de Paulo Freire assim como da sua visão da educação do educador. As principais idéias do construto teórico de Antonio Gramsci estão presentes na obra de Paulo Freire atribuindo consistência filosófica e política ao pensamento freireano. Da mesma forma, ambos têm pontos de vista que se aproximam no que diz respeito à educação dos educadores. Em particular no que ser refere ao fato de que o educador seja educado de forma a levar em consideração o "meio" no qual estão inseridos os educandos, mas também que aprendam a fazer a relação entre a escola e a vida, isto é, entre a prática pedagógica e a realidade vital na qual estão vivem os educandos. Além disso, assim como Freire defende a idéia de que o educador seja educado de maneira a acreditar na educação como prática da liberdade, Gramsci atribui à formação intelectual e moral dos intelectuais um papel significativo para que exerçam sua ação "pedagógica", tendo ao fundo e à frente a liberdade como utopia a ser atingida, pois, para ele "toda relação de hegemonia é uma relação pedagógica" (GRAMSCI, 1975, p. 1331). Ainda mais: Assim como, para Gramsci, os "circule di cultura" no interior dos conselhos de fábrica, seriam os locae da ação dos educadores, intelectuais orgânicos, em sua prática visando construção de uma revolução intelectual e moral, Freire os vê como espaços de liberdade e de construção da consciência crítica. Portanto, nossa pesquisa alem de demonstrar que os dois autores situados distantes tanto no tempo quanto no espaço geográfico, aproximam-se, mostra, ainda, a influência das bases epistemológicas de Gramsci sobre a construção da fundamentação teórica da prática pedagógica de Paulo Freire. Assim, não somente a teoria freireana da educação bebeu na fonte gramsciana, como também seu método de alfabetização foi aperfeiçoado com o aporte das idéias de Gramsci cujo contato foi iniciado durante a permanência de Paulo Freire no Chile e consolidado em Genebra nos espaços do Conselho Mundial de Igrejas, em especial a partir do seu contato com Antonio Faundez que o substituiu na direção do departamento de educação do CMI. Mostra, também, que a visão que ambos tinham da educação dos educadores, dos intelectuais orgânicos das classes subalternas, cuja ação de realizaria no sentido de construir uma nova sociedade, têm importantes pontos em comum, mostrando que ambos têm como fundamentação teórico/prática do seu pensamento e da sua ação, a fillosofia da praxis.

\section{REFERÊNCIAS}

FREIRE, P. Conscientização: teoria e prática da libertação. Uma introdução ao pensamento de Paulo Freire. São Paulo: Moraes, 1980.

FREIRE, P. Conscientización: teoria y pratica de la liberación. Buenos Aires: Busqueda, 1974a.

FREIRE, P. Educação como prática da liberdade. Rio de Janeiro: Paz e Terra, 1976.

FREIRE, P. Extensão e comunicação. Rio de Janeiro: Paz e Terra, 1997. 
FREIRE, P. Las iglesias, la educación y el proceso de liberación humana en la historia. Buenos Aires: Editorial la Aurora, 1974b.

FREIRE, P. Pedagogia da autonomia: saberes necessários à prática educativa. São Paulo: Paz e Terra, 1996

FREIRE, P. Pedagogia do oprimido. Rio de Janeiro: Paz e Terra, 1977.

FREIRE, P. Professora sim, tia não. Cartas a quem ousa ensinar. São Paulo: Olho d'Água, 1997.

FURTER, P. Les espaces de la formation. Lausanne : Presses Universitaires Romandes, 1983.

GRAMSCI, A. L'Ordine Nuovo. Torino: Einaudi, 1987.

GRAMSCI, A. Quaderni del carcere. Torino: Einaudi, 1975.

LÉVÊQUE, R. \& BEST, F. Traité des sciences pédagogiques. Paris : PUF, 1969.

MARX, K. A ideologia alemã. São Paulo: Grijalbo, 1974.

MEMI, A. Retrato do colonizado precedido do retrato do colonizador. São Paulo: Ed. Civilização Brasileira, 2004. 